\title{
Drug Utilization Review and Cost Analysis of Anticancer Drugs Used in a Tertiary Care Teaching Hospital
}

\author{
B. SAJEEV KUMAR* ${ }^{*}$ SERENE MARIA ${ }^{1}$, C. H. SHEJILA² AND PADMAJA UDAYKUMAR ${ }^{3}$
}

Department of Pharmaceutics, Ahalia School of Pharmacy, Palakkad-678 557, ${ }^{1}$ Department of Pharmacy Practice, Karavali College of Pharmacy, Mangalore-575 028, ${ }^{2}$ Medical Surgical Nursing, Manipal College of Nursing, Manipal University, Manipal-576 104, ${ }^{3}$ Department of Pharmacology, Father Muller Medical College Hospital, Mangalore-575 002, India

\section{Kumar et al.: Drug Utilization Review and Cost Analysis of Anticancer Drugs}

\begin{abstract}
The present study aimed to evaluate the trends and pattern of prescribing of anticancer drugs. The objectives of the study were to assess the rational use of anticancer drugs, to identify various types of cancer and to estimate the cost distribution of anticancer drugs. An observational, prospective study was conducted in 200 patients in oncology department. Data were collected from case reports, prescriptions and medication charts in specially designed forms. Out of 200 patients enrolled, majority were female (59.5\%) in the age group of 40-60 years (52 \%). Gastrointestinal tract cancers $(25 \%)$ were most commonly observed, followed by breast cancer $(18.5 \%)$ and genitourinary cancers $(16.5 \%)$. Cisplatin $(35 \%)$ was the most commonly prescribed anticancer drug, followed by paclitaxel $(18.5 \%)$, carboplatin $(14 \%)$, 5 -flourouracil (12.5\%) and oxaliplatin ( $7.5 \%)$. Ranitidine, dexamethasone and ondansetron were used as palliative therapy either to prevent or manage the adverse reactions of the anticancer drugs. Trastuzumab contribute to the major cost (Rs. 450 000) in the drug therapy. The average cost of drug per prescription was Rs. 11 135. The overall prescribing indicators pointed that the average number of total drugs, anticancer drugs and antibiotics were $12.22,1.73$ and 0.43 , respectively. The usage of drugs was found to be rational and about $99.38 \%$ of the drugs used were from the hospital formulary. The prescribing habits were appropriate and were in accordance with World Health Organization guidelines. The present study appeared to support best prescribing practices in order to promote cost-effective treatment and better health care delivery.
\end{abstract}

Key words: Anticancer, chemotherapy, cost analysis, oncology, prescribing pattern

Cancer has become a major burden and threat to the global society. It is one of the leading causes of death in the world. A survey by World Health Organization (WHO) indicates that 8.2 million people died from cancer in 2012 and it may rise to 19 million by $2025^{[1]}$. As per the National Institute of Cancer Prevention and Research, about 2.5 million people are suffering from cancer in India and it is the second most common disease responsible for 556400 deaths per year. This is due to lack of adequate preventive measures, delayed diagnosis and treatment of the disease. The high incidence rate of cancer could be due to genetics, mutation, hormonal changes, food habits and life style ${ }^{[2]}$.

Different treatment modalities for cancer include surgery, chemotherapy, radiation therapy, monoclonal antibody therapy and immunotherapy. The choice of the treatment depends on the site and grade of the tumor, the stage of the disease and the general state of

*Address for correspondence E-mail: drsajeev2016@gmail.com

July-August 2018 the patient. A wide range of chemotherapeutic agents are extensively used to treat cancer at different stages. Chemotherapy refers to antineoplastic drugs used to treat cancer or the combination of these drugs as a standardized treatment regimen. Cancer can be treated with a single drug or by combination therapy.

The high incidence of cancer coupled with the increment in the cost of treatment and variability in drug prices imparted a significant challenge to patients $^{[3]}$. Cancer was found to be the third highest in terms of cost for treatment and a major part of hospital inventory is of cancer drugs. It is observed that around 348 drugs enlisted in the National List of Essential

This is an open access article distributed under the terms of the Creative Commons Attribution-NonCommercial-ShareAlike 3.0 License, which allows others to remix, tweak, and build upon the work non-commercially, as long as the author is credited and the new creations are licensed under the identical terms

Accepted 15 June 2018

Revised 19 November 2017

Received 03 October 2016

Indian J Pharm Sci 2018;80(4):686-693 
Medicines were used for its treatment. Consequently, drug utilization studies (DUS) and cost analysis of anticancer drugs became an inevitable tool in the health economics.

Drug use is a complex process since optimal benefits of drug therapy in patient care may not be achieved because of under-use, overuse or misuse of these drugs. Inappropriate drug use may also lead to increased cost of medical care, antimicrobial resistance, adverse effects and patient mortality. Hence, in recent years, DUS have become a potential tool to be used in the evaluation of health care systems ${ }^{[4]}$. DUS are defined as the study of marketing, distribution, prescription and use of drugs in a society, with special emphasis on the resulting medical, social and economic consequences ${ }^{[5]}$. DUS provide an insight of the efficacy and pattern of drug use, and the quality and outcome of use $\mathrm{e}^{[6,7]}$.

The present study aimed to analyze and evaluate the trends and patterns of prescribing anticancer drugs. It also aimed to provide a review of prescribing practices to physicians, which can be used to promote costeffective treatment and better health care delivery. The objectives of the study were to assess the rational use of anticancer drugs, identify the various types of cancer and the commonly prescribed drugs, find out the cost distribution of anticancer drugs and analyze the prescribing indicators.

\section{MATERIAL AND METHODS}

The study was conducted in oncology department of a tertiary care teaching hospital (Fr. Muller Medical College Hospital, Mangalore) over a period of $6 \mathrm{mo}$. An observational, prospective study was conducted in various wards (oncology, radiotherapy and paediatrics) of oncology department. The study was performed after obtaining the necessary ethical clearance from the Institutional Ethics Committee. A total of 200 patient case reports, prescriptions and medication charts were used for the study. The cost details were collected from CIMS, Drugs up-to-date, pharmacy bills and hospital formulary. The inclusion criteria were inpatients of all age groups and sex from oncology, radiotherapy and paediatrics wards, receiving at least one anticancer drug. Patients who were pregnant and having insufficient records and data were excluded from the study. Data was collected and entered in specially designed patient data entry forms. Necessary prescription parameters needed for the study were observed. Sample size was calculated using online Creative Research Systems survey software. An Excel-based tool was used for systematic data sampling and analysis. The survey results were presented in numbers and visualised in histograms. WHO core prescribing indicators was compiled at the end of the study to know the amount of prescriptions with polypharmacy, percent of prescriptions with injectables, antibiotics and percent of drugs prescribed from Essential Drugs list.

The collected data was analysed using descriptive statistics. The data were entered in Microsoft Excel (Windows 7; Version 2007). Descriptive statistics such as frequencies and percentage were calculated for demographic and clinical variables and were represented in tables.

\section{RESULTS AND DICUSSION}

During the study period around 200 cancer patients were found to be admitted in oncology department, which include patients in chemotherapy, radiotherapy and paediatric ward. The sample size was planned based on the average number of inpatients admitted and recorded in the earlier six months of the study period. For outlining drug use, we selected prescriptions containing at least one anticancer drug from the multiple prescriptions in the case records with followup visits. Thus, if the initial prescription was continued, it was regarded as the same prescription for the given duration. Any changes in that prescription was noted for calculating the drug consumption.

The distribution of patients in chemotherapy, radiotherapy and paediatric wards were 146, 50 and 4, respectively. These included 51 males and 95 females in chemotherapy, 27 males and 23 females in radiotherapy, and 3 males and 1 female in the paediatric ward. Female cancer patients were more in oncology ward, while male cancer patients were high in the radiotherapy ward. Out of 200 prescriptions analysed, the number of males getting treatment was 81 , while the females accounted for 119 patients.

The age-wise distribution pattern of patients for treatment of cancer is shown in the Table 1. The study showed that the maximum prevalence was in between the age group of 40-50 y and the least in the age group of 0-10 y. A chi-square test was used to study the test of significance, $\mathrm{p}<0.05$ was observed, representing the variables were independent and no significant observation in number of cancer cases with respect to male or female.

During the study period, 35 types of cancer cases were detected. Types and percent of each type of cancer 
TABLE 1: AGE-WISE DISTRIBUTION OF CANCER PATIENTS

\begin{tabular}{lcccc}
\hline $\begin{array}{l}\text { Age groups } \\
\text { (years) }\end{array}$ & $\begin{array}{c}\text { Total } \\
\text { number of } \\
\text { patients }(\mathbf{n})\end{array}$ & $\begin{array}{c}\text { Number } \\
\text { of males } \\
(\mathbf{n})\end{array}$ & $\begin{array}{c}\text { Number } \\
\text { of females } \\
(\mathbf{n})\end{array}$ & $\begin{array}{c}\text { Total } \\
\text { patients } \\
(\%)\end{array}$ \\
\hline $0-10$ & 4 & 3 & 1 & 2 \\
$10-20$ & 7 & 6 & 1 & 3.5 \\
$20-30$ & 12 & 3 & 9 & 6 \\
$30-40$ & 24 & 9 & 15 & 12 \\
$40-50$ & 54 & 20 & 34 & 27 \\
$50-60$ & 50 & 20 & 30 & 25 \\
$60-70$ & 40 & 18 & 22 & 20 \\
$70-80$ & 9 & 2 & 7 & 4.5 \\
\hline
\end{tabular}

TABLE 2: TYPES AND NUMBER OF PATIENTS OBSERVED WITH CANCER

\begin{tabular}{|c|c|c|c|}
\hline Type of cancer & $\begin{array}{c}\text { Number of } \\
\text { patients } \\
(\%) \\
\end{array}$ & Type of cancer & $\begin{array}{c}\text { Number of } \\
\text { patients } \\
(\%)\end{array}$ \\
\hline Breast & 37 (18.5 \%) & $\begin{array}{l}\text { Respiratory } \\
\text { system }\end{array}$ & $10(5 \%)$ \\
\hline Head and neck & 36 (18\%) & Lung & 9 \\
\hline Tongue & 12 & Aveolar & 1 \\
\hline Buccal mucosa & 7 & GIT & $50(25 \%)$ \\
\hline Oropharynx & 6 & Stomach & 17 \\
\hline Pyriform fossa & 3 & Colon & 11 \\
\hline Maxillary & 2 & Esopharynx & 10 \\
\hline Nasoparynx & 1 & Rectal & 8 \\
\hline Hypopharynx & 1 & Pancreas & 2 \\
\hline Hard palate & 1 & $\begin{array}{l}\text { Pseudomyxoma } \\
\text { peritonea }\end{array}$ & 2 \\
\hline Supraglottis & 1 & $\begin{array}{c}\text { Genitourinary } \\
\text { tract }\end{array}$ & $33(16.5 \%)$ \\
\hline Larynx & 1 & Ovary & 15 \\
\hline \multirow[t]{3}{*}{ RMT } & 1 & Cervix & 12 \\
\hline & & Endometrial & 5 \\
\hline & & Vaginal & 1 \\
\hline Others & 27 (16.5 \%) & Brain & $3(1.5 \%)$ \\
\hline $\mathrm{NHL}$ & 11 & $\begin{array}{l}\text { Glioblastoma } \\
\text { multiforma }\end{array}$ & 2 \\
\hline ALL & 10 & $\begin{array}{c}\text { Anaplastic } \\
\text { astrocytoma }\end{array}$ & 1 \\
\hline$A M L$ & 3 & Skeletal system & $4(2 \%)$ \\
\hline CML & 1 & Ewing's sarcoma & 2 \\
\hline Neuroendocrine & 1 & $\begin{array}{c}\text { Pleomorphic } \\
\text { carcinoma of } \\
\text { wrist }\end{array}$ & 1 \\
\hline $\begin{array}{l}\text { Multiple } \\
\text { myeloma }\end{array}$ & 1 & $\begin{array}{l}\text { Extra skeletal } \\
\text { osteosarcoma }\end{array}$ & 1 \\
\hline
\end{tabular}

RMT: Retromolar trigone, NHL: non-Hodgkin lymphoma, ALL: acute lymphoblastic leukaemia, AML: acute myelocytic leukaemia and CML: chronic myelogenous leukaemia

were reported in Table 2. Among all types of cancers, gastrointestinal (GI) cancer (25\%) was found to be the most prevalent followed by breast cancer $(18.5 \%)$ and head and neck cancer (18\%). Brain cancer $(1.5 \%)$ and bone cancer $(1.3 \%)$ were found to be the least prevalent. Fig. 1 showed tissue site and organ-wise distribution of cancer in males and females. In males, head and neck cancer $(15.5 \%)$ were more predominant, followed by GI cancers $(13 \%)$. Genitourinary cancer was found to be the least predominant in males with no report of inpatients during the study period. In females, breast cancer $(18 \%)$ was found to be the most predominant, followed by genitourinary cancer $(16.5 \%)$. Cancers of the brain and skeletal system was found to be the least predominant with just two inpatients reported during the entire study period.

Out of 200 cancer patients analysed, 87 patients were prescribed with single drug therapy while 89 with multiple drug therapy. Around 14 prescriptions had three drugs each, 7 prescriptions had 4 drugs and 3 prescriptions had 5 drugs prescribed. Majority of the anticancer drugs (113 prescriptions) were prescribed alone or in combination of two. The prescribing pattern of anticancer drugs was shown in Table 3. In the chemotherapy ward, cisplatin $(n=8)$ was the most commonly used drug in males, while in females paclitaxel $(n=27)$ was normally used. In the radiology ward, cisplatin was the most commonly used drug among both males $(n=19)$ and females $(n=17)$. Methotrexate $(n=2)$ and asparaginase $(n=2)$ were commonly used in males in the paediatric ward, while in females daunorubicin was used.

The therapeutic class-wise prescribing pattern of anticancer drugs was presented in Table 4. Cytotoxic drugs $(90 \%)$ were the most commonly prescribed, while hormonal $(1.4 \%)$ and other drugs $(1.4 \%)$ were the least commonly prescribed. Among cytotoxic drugs, platinum coordination complexes $(n=113)$ were the most commonly used followed by antimetabolites

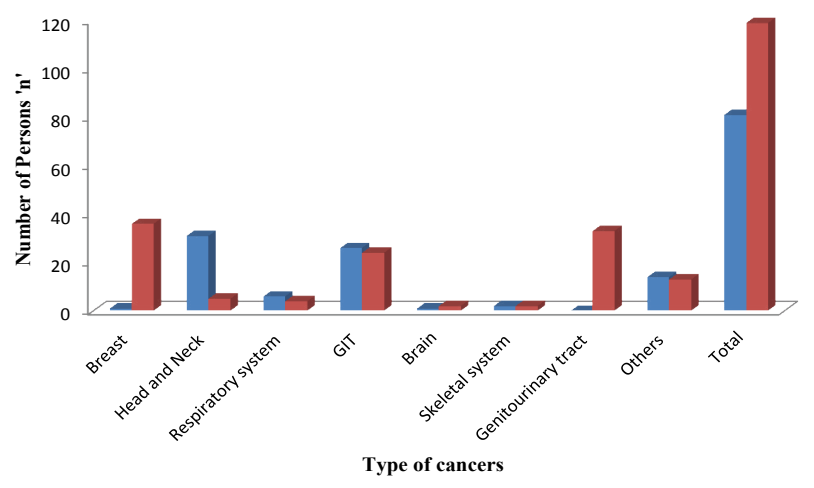

Fig. 1: Tissue site and organ-wise distribution of cancer in male and female

$\mathbf{P}<0.05$; no significant observation in number of cancer cases and variables were independent; $\square$ male, $\square$ female 


\begin{tabular}{|c|c|c|c|c|c|c|}
\hline \multirow{2}{*}{ Drugs } & \multicolumn{2}{|c|}{ Chemotherapy } & \multicolumn{2}{|c|}{ Radiology } & \multicolumn{2}{|c|}{ Paediatric } \\
\hline & Males & Females & Males & Females & Males & Females \\
\hline Cisplatin & 18 & 16 & 19 & 17 & - & - \\
\hline Paclitaxel & 5 & 27 & 2 & 4 & - & - \\
\hline Carboplatin & 5 & 20 & 1 & 2 & - & - \\
\hline $5 \mathrm{FU}$ & 13 & 10 & 2 & - & - & - \\
\hline Oxaliplatin & 9 & 7 & 1 & - & - & - \\
\hline Gemcitabine & 4 & 8 & - & 1 & - & - \\
\hline Capecetabine & 6 & 5 & 3 & 1 & - & - \\
\hline Cyclophosphamide & 5 & 10 & - & - & - & - \\
\hline Doxorubicin & 5 & 6 & - & - & - & - \\
\hline Etoposide & 5 & 7 & - & - & - & - \\
\hline Vincristine & 5 & 5 & - & 1 & - & - \\
\hline Docetaxel & 2 & 6 & - & - & - & - \\
\hline Methotrexate & 5 & 1 & - & - & 2 & \\
\hline Rituximab & 2 & 5 & 1 & - & - & - \\
\hline Irinotecan & 2 & 5 & - & - & - & - \\
\hline Trastuzumab & - & 5 & - & 1 & - & - \\
\hline Epirubicin & 3 & 3 & - & - & - & - \\
\hline Cytarabine & 3 & 3 & - & - & - & - \\
\hline Pemetrexed & 2 & 2 & - & - & - & - \\
\hline Zoledronic acid & 1 & 2 & - & - & - & - \\
\hline Letrozole & - & 4 & - & - & - & - \\
\hline Imatinib & 2 & 1 & - & - & - & - \\
\hline Daunorubicin & 5 & 1 & - & - & - & 1 \\
\hline Tamoxifen & - & 3 & - & - & - & - \\
\hline $6 \mathrm{MP}$ & 3 & - & - & - & - & - \\
\hline Hydroxyurea & - & 3 & - & - & - & - \\
\hline Bevacizumab & - & 2 & - & - & - & - \\
\hline Sorafenib & - & 3 & - & - & - & - \\
\hline Temozolamide & - & 1 & 1 & 1 & - & - \\
\hline Asparaginase & - & 1 & - & - & 2 & - \\
\hline Cetuximab & - & - & 1 & - & - & - \\
\hline Bleomycin & 1 & - & - & - & - & - \\
\hline Ifosamide & 1 & 1 & - & - & - & - \\
\hline Lenalidomide & - & - & - & - & - & - \\
\hline Dacarbazine & 1 & - & - & - & - & - \\
\hline Thioguanine & - & - & - & 1 & - & - \\
\hline Vinblastine & 1 & - & - & - & - & - \\
\hline Pertuximab & - & 1 & - & - & - & - \\
\hline
\end{tabular}

Values denote number of patients ' $n$ ', FU: fluorouracil. MP: mercaptopurine

$(n=75)$ and miscellaneous drugs $(n=5)$ were the least used. Among targeted drugs, unarmed monoclonal antibodies $(\mathrm{n}=14)$ were the most commonly used drugs and ECF receptor inhibitors $(\mathrm{n}=2)$ and angiogenesis inhibitors $(n=2)$ were the least commonly prescribed. Aromatase inhibitors $(n=4)$ were the most commonly used among hormonal drugs, while selective oestrogen modulators $(n=3)$ were the least used. The most commonly used hormonal drugs were tamoxifen $(n=3)$ among selective oestrogen modulators and letrozole $(n=4)$ among aromatase inhibitors. The other commonly used drug was zoledronic acid $(n=3)$ and the least used were lenalidomide $(\mathrm{n}=1)$ and pertuximab $(\mathrm{n}=1)$. The most commonly used alkylating agents were cyclophosphamide $(n=15)$, cisplatin $(n=70)$, capecetabine $(\mathrm{n}=15)$, paclitaxel $(\mathrm{n}=38)$, etoposide $(\mathrm{n}=12), \quad$ irinotecan $(\mathrm{n}=7), \quad$ doxorubicin $\quad(n=11)$ among antibiotics and hydroxyurea $(n=3)$ among miscellaneous drugs.

The cost distribution of anticancer drugs has been given in Table 5. The study revealed that trastuzumab contributed to the major cost in drug therapy (Rs. 450 000), followed by paclitaxel (Rs. 407 898), rituximab (Rs. 229 977), bevacizumab (Rs. 176 538), 


\begin{tabular}{|c|c|c|c|}
\hline Type & Group and number of agents $(n)$ & Name & Number of patients $(n)$ \\
\hline \multirow{27}{*}{$\begin{array}{l}\text { Cytotoxic drugs } \\
(322,90 \%)\end{array}$} & \multirow{4}{*}{ Alkylating agents (20) } & Cyclophosphamide & 15 \\
\hline & & Temozolamide & 3 \\
\hline & & Ifosamide & 1 \\
\hline & & Dacarbazine & 1 \\
\hline & \multirow{3}{*}{ Platinum coordination complexes (113) } & Cisplatin & 70 \\
\hline & & Carboplatin & 28 \\
\hline & & Oxaliplatin & 15 \\
\hline & \multirow{8}{*}{ Antimetabolites (75) } & $5 \mathrm{FU}$ & 25 \\
\hline & & Gemcitabine & 13 \\
\hline & & Capecetabine & 15 \\
\hline & & Methotrexate & 8 \\
\hline & & Cytarabine & 6 \\
\hline & & Pemetrexed & 4 \\
\hline & & $6 \mathrm{MP}$ & 3 \\
\hline & & Thioguanine & 1 \\
\hline & \multirow{4}{*}{ Microtubule damaging agents (58) } & Paclitaxel & 38 \\
\hline & & Docetaxel & 8 \\
\hline & & Vincristine & 11 \\
\hline & & Vinblastine & 1 \\
\hline & Topoisomerase-2 inhibitors (12) & Etoposide & 12 \\
\hline & Topoisomerase- 1 inhibitors (7) & Irinotecan & 7 \\
\hline & \multirow{4}{*}{ Antibiotics (24) } & Doxorubicin & 11 \\
\hline & & Epirubicin & 6 \\
\hline & & Daunorubicin & 6 \\
\hline & & Bleomycin & 1 \\
\hline & \multirow{2}{*}{ Miscellaneous (5) } & Hydroxyurea & 3 \\
\hline & & Asparaginase & 2 \\
\hline \multirow{6}{*}{$\begin{array}{l}\text { Targeted drugs } \\
(21,5.8 \%)\end{array}$} & Tyroxine protein kinase inhibitors (3) & Imatinib & 3 \\
\hline & \multirow{2}{*}{ ECF receptor inhibitors (2) } & Geftinib & 1 \\
\hline & & Cetuximab & 1 \\
\hline & Angiogenesis inhibitors (2) & Bevacizumab & 2 \\
\hline & \multirow{2}{*}{ Unarmed monoclonal antibody (14) } & Rituximab & 8 \\
\hline & & Trastuzumab & 6 \\
\hline Hormonal drugs & Selective estrogen modulators (3) & Tamoxifen & 3 \\
\hline \multirow[t]{2}{*}{$(7,1.4 \%)$} & Aromatase inhibitors (4) & Letrozole & 4 \\
\hline & & Zoledronic Acid & 3 \\
\hline Others & & Sorafenib & 2 \\
\hline \multirow[t]{2}{*}{$(7,1.4 \%)$} & & Lenalidomide & 1 \\
\hline & & Pertuximab & 1 \\
\hline Total & & & 200 \\
\hline
\end{tabular}

pemetrexed (Rs. 137 570), docetaxel (Rs. 134 829). Tamoxifen (Rs. 458.55), mercaptopurine (Rs. 278.8), vinblastine (Rs. 258), letrozole (Rs. 228), hydroxyurea (Rs. 117.99) were the least expensive anticancer drugs. Table 6 contained the prescribing indicators in anticancer therapy used for rational use of drugs.

Cancer is a group of diseases involving abnormal cell growth with potential to invade or spread to any parts of the body ${ }^{[8]}$. With a million of new cases being reported every year, cancer seems to be tightening its grip on India. Experts say that the incidence of cancer is expected to rise five-fold by 2025. Ignorance among the public, delayed diagnosis and treatment and high treatment cost has given cancer the distinction of being a killer disease.

The diverse drug utilization process and the increased cost incurred on drug therapy could put severe burden on patient's treatment and cancer management. These facts need to be viewed as it might create awareness among health care professionals so as to support and manage the therapy. This might also prompt the patients to avoid noncompliance with the therapy. 
TABLE 5: COST DISTRIBUTION OF ANTICANCER DRUGS

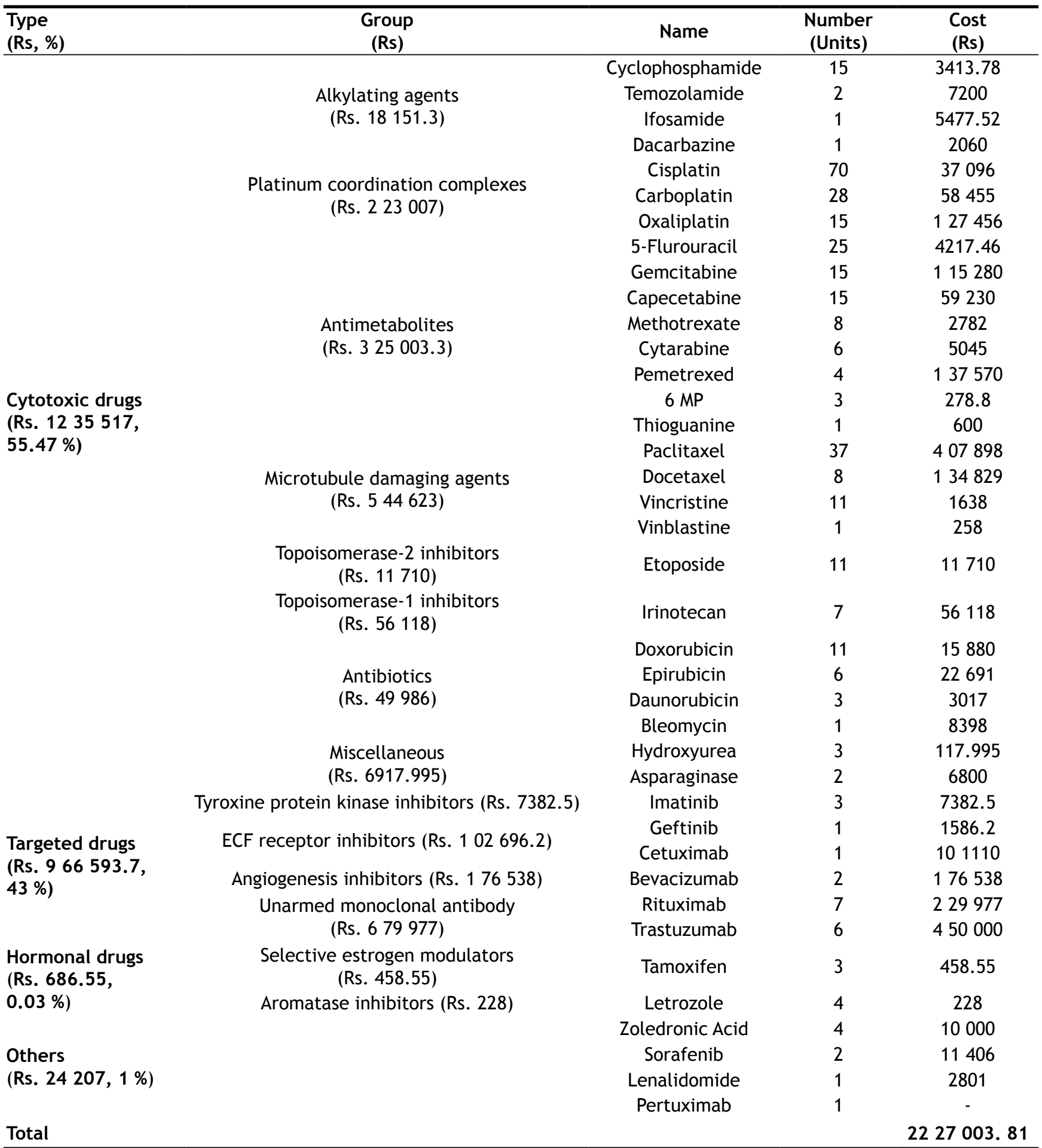

Hence, proper monitoring of cancer treatment and drug therapy are required for the wellbeing of the patient.

The present study was aimed to analyse the drug utilization review and cost analysis of anticancer drugs used in a tertiary care teaching hospital in the district of Dakshina Kannada. During the study period, around 200 cancer patients were admitted in oncology department and most of them were in chemotherapy ward. This revealed that the majority of the cancers were treated either by chemotherapy or through both chemotherapy and radiotherapy. Certain cases like cancer of vagina and cervix, cancer of buccal cavity, and cancer of tongue were treated by radiotherapy.

In our study, it was observed that more females (119) were admitted with cancer. The reason could be unknown or may be variable as discussed by 
TABLE 6: WHO PRESCRIBING INDICATORS

\begin{tabular}{lc}
\hline Prescribing indicators & Findings \\
\hline $\begin{array}{l}\text { Average number of anticancer drugs per } \\
\text { prescription }\end{array}$ & 1.73 \\
$\begin{array}{l}\text { Average number of antibiotics per } \\
\text { prescription }\end{array}$ & 0.43 \\
Average number of drugs per prescription & 12.22 \\
$\begin{array}{l}\text { Average number of injections per prescription } \\
\text { Percent of encounters with an antibiotic }\end{array}$ & 5.99 \\
prescribed & $25.50 \%$ \\
Percent of encounters with an injection & $93.50 \%$ \\
prescribed & $20.24 \%$ \\
Percent of drugs prescribed by generic names & $\begin{array}{l}\text { Percent of drugs prescribed by brand names } \\
\text { Percent of drugs prescribed by formulary }\end{array}$ \\
$\begin{array}{l}\text { Average cost of anticancer drugs per } \\
\text { prescription }\end{array}$ & $99.38 \%$ \\
\hline
\end{tabular}

Dave et al. suggesting causes due to hormonal changes during menopause, use of oral contraceptives, hormone replacement therapy and life style. The number of cancer cases in paediatric unit was very less $(<5)$. The incidence of cancer rate (both males and females) was more in the age group of 40-60 y. In our observation, $52 \%$ of adults had high incidence rate of cancer, while it was only $5 \%$ in children. This could be due to change in life style, habits or ageing. Aging is the major cause of cancer due to decreased immunity, the hormonal, other physiological and functional changes that occur in the body, which might lead to activation of pro-oncogenes ${ }^{[9]}$. In a similar study conducted by Kulkarni et al. ${ }^{[7]}$ the average age group was between 30-70 y. The result clearly revealed that age is the major factor responsible for cancer. With age the organs become susceptible to cancer due to hormonal imbalance, increase in number of loci of chronic proliferation and the decline in immune surveillance. This also specifies that at young age the incidence of cancer is lower.

There are more than 200 different types of cancers detected and the incidences of different cancer depended upon various socioeconomic and ethnic concerns ${ }^{[10]}$. Cancer was found to affect every systems of the body without revealing the specific nature of the disease. In our observation, out of 35 types of cancer detected, GI cancer $(25 \%)$ was more prevalent, followed by breast cancer $(18.5 \%)$ and head and neck cancer (18\%). Head and neck cancer was more prevalent in males $(15.5 \%)$, while breast cancer was higher in females $(18.5 \%)$. In a study conducted by Siddiqua et al., 58 types of cancer were observed and the major incidence was lung cancer (17.9\%), followed by breast cancer $(17 \%)$ and cancer of cervix (14.1\%). Cancer of the genitourinary tract was $16.5 \%$, with most of the patients treated for ovarian $(\mathrm{n}=15)$ and cervical cancer $(n=12)$. The distribution of cancer in tissue site and organs show female predominant.

Different treatment modalities have been available for cancer and these include surgery, chemotherapy, radiation, immunotherapy, biologic therapy and cryosurgery. Most of the cancers were treated by chemotherapy. In our observation more drugs were prescribed in chemotherapy ward compared to radiotherapy ward. Among them, cisplatin (17\%), paclitaxel (16\%), carboplatin (12.5\%), 5-flourouracil (5-FU, $11.5 \%)$ and oxaliplatin $(8 \%)$ accounted for high use. The use of cisplatin $(18.5 \%)$ and 5-FU $(13 \%)$ were also higher in a related study conducted by Dave et al. at PDU Govt. Medical College and Hospital, Gujarat ${ }^{[11]}$. This specifies the need for regular monitoring of these drugs for adverse effects in organs due to their wide prescription.

The major therapeutic class of drug prescribed for cancer was cytotoxic drugs $(n=322,90 \%)$. These drugs are known to cause severe side effects. Chemotherapeutic agents have a narrow therapeutic index and the dosage needed to achieve the therapeutic effect would also cause severe toxic effects ${ }^{[11]}$. In the present study, cisplatin was widely used as a chemotherapeutic drug and its major side effect is nephrotoxicity. In our observation, cisplatin was given as rapid infusions along with nephroprotective agents such as mannitol and $\mathrm{MgSO}_{4}^{[12]}$.

Consequently, a proper therapeutic drug monitoring process is necessary for chemotherapeutic agents. The toxic effects could be managed effectively by individualizing the drug therapy. Many of the side effects of the cancer therapy can managed with adjuvant drugs like antidiarrheals, laxatives, antihistamines, immunosuppressants and gastric protectants.

Cost analysis studies provide an estimation of the finances that may be included in drug therapy. The data showed that trastuzumab contributed more in cost in spite of lesser number of units being prescribed $(n=6)$. This emphasized the necessity of inventory control in hospital pharmacy. The average cost of anticancer drugs per prescription was Rs 11 135. In a particular study conducted by Wani et al. ${ }^{[3]}$ the unit cost of inpatient chemotherapy on an average was calculated to be Rs. 5725.12 per patient per bed day. 
The cost distribution per class of therapeutic agents showed cytotoxic agents accounted for the major cost (Rs. 1235 517), followed by targeted drug systems (Rs. 966 593.7) and others drugs (Rs. 24 207). The minimal cost distribution was for hormonal drugs (Rs. 686.55). Cost difference of drugs among hospitals may exist and it may depend upon the product type and service rendered by the organization. This study revealed that the average cost of anticancer therapy is very high. The high cost of chemotherapeutic agents made it unaffordable to common people in a country like India. Cost analysis is particularly relevant in chronic diseases like cancer that weigh heavily on health expenditures. In case of cancer, most of the health care cost is imparted by the drugs. The increasing prevalence of cancer and the continuously rising expense of its treatment influence the prescribing patterns among physicians and compliance by the patients. Therefore, use of anticancer drugs has to be regularly monitored and controlled. Analysis of cost of anticancer therapy will be useful for educating and informing the healthcare policy makers in planning a cost-effective drug therapy. A difficulty that has encountered during cost analysis was that few drugs were prescribed by their generic names. The prescribing indicator signifies that the average number of cytotoxic drugs (1.73) per prescription was appropriate and comparatively lower than that of similar studies conducted in Brazil (2.4), Jordan (2.3) and in other places in India (2.7) ${ }^{[13]}$.

Drug utilization review and cost distribution analysis for anticancer drugs are essential among health care professionals as it highlights the importance of assessing optimal drug use with cost effectiveness. The scope is possible only through regular update of medical knowledge, by frequently attending continuing medical education programs by the physicians. The process of initiating chemotherapy is a complex task, since it involves high cost and imposes severe economic burden on the patient. The study implies that most of the anticancer drugs were prescribed either single or in combination for improved therapy and are highly expensive. The complexity in prescribing can be improved by introducing cost controlling policies and new systemic interventions that might increase the quality of patient care. The prescribing pattern and cost distribution have to be examined from time to time so as to manage the inventory control in hospital pharmacy. The study concluded that the usage of drugs was rational and about $99.38 \%$ of drugs used were from the hospital formulary. The prescribing habits were appropriate and in accordance with WHO guidelines.

\section{Acknowledgements:}

The authors would like to thank Rev. Fr. Patrick Rodrigues, Director, Father Muller Medical College Hospital (FMMCH) and Charitable Institutions, Mangalore for granting us the necessary permission for the study. The authors also thank all the healthcare professionals of Oncology Unit of FMMCH for their constant support and guidance.

\section{Conflict of interest:}

The authors declare that they have no conflict of interest.

\section{REFERENCES}

1. Cancer. World Health Organization: WHO. Available from: http://who.int/cancer/en.

2. Otoom S, Batieha A, Hadidi H, Hasan M, Al-Saudi K. Evaluation of drug use in Jordan using WHO prescribing indicators. East Mediterr Health J 2002;8:537-43.

3. Wani MA, Tabish SA, Jan FA, Khan NA, Wafai ZA, Pandita KK. Cost analysis of in-patient cancer chemotherapy at a tertiary care hospital. J Cancer Res Ther 2013;9:397-401.

4. Sachdeva PD, Patel BG. Drug utilization studies- Scope and future perspectives. IJPBR 2010;1:11-7.

5. Truter I. A review of drug utilization studies and methodologies. Jordan J Pharm Sci 2008;1:91-102.

6. Introduction to Drug Utilization Research. World Health Organization: WHO. Available from: http://apps.who.int/ medicinedocs/en/d/Js4876e/.

7. Kulkarni MD, Hussaini SA, Padwal SL, Khandelwal PN, Doifode SM, More PP. Drug utilization review of anticancer drugs in cancer outpatient department of the Government Medical College, Aurangabad. Int J Basic Clin Pharmacol 2014;3:879-83.

8. Cancer Fact sheets. World Health Organization: WHO. Available from: http://www.who.int/mediacentre/factsheets.

9. Siddiqua A, Jafar H, Tabassum N, Firdous S, Tabassum K. Drug utilization evaluation of anticancer drugs. Am J Pharmtech Res 2014;4:692-702.

10. Kirthi C, Afzal A, Reddy M, Ali SA, Yerramilli A, Sharma S. A study on the adverse effects of anticancer drugs in an oncology center of a tertiary care hospital. Int J Pharm Pharm Sci 2014;6:580-83.

11. Dave DJ, Pillai A, Shah DV, Agarwal S, Goel A. An analysis of utilization pattern of anticancer drugs in diagnosed cases of carcinoma in a tertiary care teaching hospital. Int J Basic Appl Med Sci 2014;4:251-59.

12. Mallik S, Palaian S, Ojha P, Mishra P. Pattern of adverse drug reactions due to cancer chemotherapy in a tertiary care teaching hospital in Nepal. Pak J Pharm Sci 2007;20:214-18.

13. Khan MK, Thapa RK, Adhikari DS, Rajbhandari M, Dwa $\mathrm{P}$, Shrestha $\mathrm{S}$, et al. Evaluation of cancer prevalence and cytotoxic medication prescribing in central region of Nepal. Kathmandu Univ J Sci Eng Technol 2013;9:189-99. 